\title{
Effects of Si Content on Microstructureand Mechanical Properties of 8079 Aluminum Alloy
}

\section{Linhui ZHANG, Xiaoshu KANG, Binnian ZHONG*}

Qinghai Provincial Key Laboratory of New Light Alloys, Qinghai Provincial Engineering Research Center of High Performance Light Metal Alloys and Forming, Qinghai University, Xining, 810016, PR China

\section{*Corresponding Author: Binnian ZHONG, Qinghai Provincial, China; bnzhong@qhu.edu.cn}

\begin{abstract}
:
Because of high strength and low breaking rate, 8079 aluminum alloy has become the main material of double zero aluminum foil. However, there are still many problems in the manufacturing process, such as broken belt, pinhole and so on. As the main influencing element, Si has a great influence on the alloy. In this work, the influences of Si with various contents on microstructural evolution and mechanical properties of 8079 aluminum alloy were analyzed by energy dispersive spectrometer (EDS), optical microscope (OM), $\mathrm{X}$-Ray diffraction analyzer (XRD), universal testing machine and Vickers hardness tester. The results showed that the primary Si phase was tiny and dispersed in the alloy when the content of $\mathrm{Si}$ is less than $1.3 \%$. As the second phases dispersion strengthening, the Si phase can improve the strength of the alloy. However, when the Si content was too high, the Si phase increased and coarsened. Meanwhile, Fe-rich phase which increased by Si decreased the fine grain strengthening and the second phases strengthening mechanism. The coarse Si phase and the Fe-rich phase are brittle phase, which are easy to become the crack source in the process of material deformation and reduce the strength and toughness of the alloy. The mechanical property test shows that the performance of 8079 aluminum alloy is the best when the Si content is $1.3 \%$.

Keywords: 8079 aluminum alloy; Si; microstructure; mechanical properties
\end{abstract}

\section{Introduction}

8079 aluminum alloy which replaced 1235 aluminum alloy ${ }^{[1]}$ has become the main raw material of double zero aluminum foil (thickness $5 \sim 7 \mu \mathrm{m}$ ) due to many advantages such as high tensile strength, small number of pinholes and good elongation ${ }^{[2-4]}$. But in the actual production process, there are many quality defects such as scratch, microcrack or foreign impurity pressing on the surface of the foil during the last pass of rolling ${ }^{[5,6]}$, which greatly improve the production cost and increase the safety risks of the foil material. What on earth is the cause of these? On the one hand, the operation technology is not mature. The casting parameters and rolling parameters are optimized to change the center segregation and obtain the appropriate thickness of foil products. On the other hand, it is related to the proportion of components. The content of Fe and Si has a greater impact on the comprehensive performance of 8079 aluminum alloy ${ }^{[7]}$.

The mechanical performance of 8079 aluminum alloy depends on the morphology, size and distribution of a-Al and other phases ${ }^{[8]}$. Fe and Si are the main elements of 8079 aluminum alloy ${ }^{[9-11]}$, which have significant influence on its microstructure and mechanical properties. The solubility of Fe in 8079 aluminum alloy is relatively low, and the second phases mainly composed of $\mathrm{Al}_{3} \mathrm{Fe}$ will be enriched at the grain boundary of the alloy ${ }^{[12]}$. The Fe-rich phases with needle like or platy shape are leading to matrix splitting, and then making the plasticity of aluminum foil decrease during rolling. The Fe-rich phase also becomes the source of crack propagation which develops into pinhole ${ }^{[13,14]}$. However, proper $\mathrm{Fe}$ content has the effect of fine grain strengthening and second phases strengthening, which makes 8079 aluminum foil have higher tensile strength, elongation and reduces surface defects such as pores and pinholes. At the same time, Si can also reduce the number of pinholes in aluminum foil. It has been shown that the residual amount of solid solution $\mathrm{Si}$ in the alloy is less, and most of $\mathrm{Si}$ is easy to form (AlFeSi) phase with $\mathrm{A} 1$ and $\mathrm{Fe}{ }^{[15,16]}$.

The second phases in the double zero aluminum foil blank mainly consists of $\alpha$-(AlFeSi) phase of skeleton and round particles, $\beta$-(AlFeSi) phase of needle and disk, and $\theta-\left(\mathrm{A} 1_{3} \mathrm{Fe}\right)$ phase of needle compound. The $\theta$ phase is the only $\mathrm{Al}-\mathrm{Fe}$ equilibrium phase, and the $\alpha-(\mathrm{AlFeSi})$ phase is easy 
to be broken in the process of aluminum foil deformation ${ }^{[17,18]}$. The solubility of larger acicular $\beta$-(AlFeSi) phase in aluminum matrix is smaller during homogenization. During the rolling process of 8079 aluminum alloy foil, the hardness and strength of the foil increase with work hardening, while the plasticity decreases. When the size of the acicular phase $(\beta, \theta)$ is larger than $5 \mu \mathrm{m}$, it is easy to become a crack source and then expand into a pinhole. In addition, the rolling performance is also related to the distribution of the second phases in the Al matrix. If the distribution of the second phases in the matrix is not uniform, the deformation will be uneven, then pinholes will be formed, and the work hardening rate of the alloy will be increased ${ }^{[19]}$. For aluminum foil materials, the grains are two-dimensional distribution and the grain boundary is plane network distribution. A small amount of the second phases at the grain boundary will still destroy its overall continuity. So the precipitation of the second phases at the grain boundary should be minimized in the production of aluminum foil ${ }^{[20]}$.

Therefore, the effective way to improve the mechanical properties of 8079 aluminum alloy foil is to reduce the grain size and control the generation of harmful second phases [21]. The content of Si in 8079 aluminum alloy is small. The purpose of this paper is to study the effect of Si content on the microstructure and mechanical properties of 8079 aluminum alloy, improve the comprehensive properties of 8079 aluminum alloy, optimize the composition range of 8079 aluminum alloy aluminum foil blank, and steadily improve the quality of aluminum foil.

\section{Experimental}

The $\mathrm{Al}$ and $\mathrm{Al}-\mathrm{Mg}, \mathrm{Al}-\mathrm{Si}, \mathrm{Al}-\mathrm{Fe}, \mathrm{Al}-\mathrm{Cu}$ alloys ingots with a mass fraction of $\mathrm{Si}$ were $0 \%$ and $1.1 \% \sim 1.5 \%$ were melted up to $750^{\circ} \mathrm{C}$ in a $5 \mathrm{~kg}$ ceramic crucible by using an electrical resistance furnace. After they were completely melted, being stirred and cleaned off, the melt was poured into a steel mold that was preheated to $200^{\circ} \mathrm{C}$. The casting $(\varphi 40 \mathrm{~mm}$, approximately $2 \mathrm{~kg}$ ) was subsequently cut into $10 \times 10 \times 10$ $\mathrm{mm}$ and dog-bone-shaped blocks by wire cutting machine. Each square specimen was polished and then etched by Keller's reagent for about $40 \mathrm{~s}$ at room temperature.

The microstructures of the specimens were examined by optical microscope (OM). The distribution of the elements in some of the samples was investigated by energy dispersion scope (EDS). The phase composition in 8079 aluminum alloys was measured by X-Ray diffraction analyzer (XRD). The Vickers micro-hardness of the samples was tested by the Vickers Indenter (HR-150B) at room temperature with a load of $200 \mathrm{~g}$ and a dwell time of 10 s. After the bone sample was polished, tensile experiments were carried out at room temperatures using an Instron machine with a constant displacement rate of $0.5 \mathrm{~mm} / \mathrm{min}$. In this work, the number of tested samples was three to five.

\section{Results and discussion}

\subsection{Microstructure analysis}

Figure 1 is XRD pattern of 8079 aluminum alloy with different $\mathrm{Si}$ content. It can be observed that there is $\mathrm{a}-\mathrm{Al}$ phase in the all alloys. When the Si content is less than $1.4 \%$, there is only the peak of aluminum phase in the diffraction pattern, the content of other phases below detection range in the alloy is less. When the Si content is $1.5 \%$, the peak strength of $a-\mathrm{Al}$ phase decreases obviously, the Si phase and (AlFeSi) phase increase. It may be that the Si phase grows up and the aggregation of Si particles often blocks the continuous contact of $\mathrm{Al}$ phase and produces more $(\mathrm{AlFeSi})$ phase with the increase of Si content.

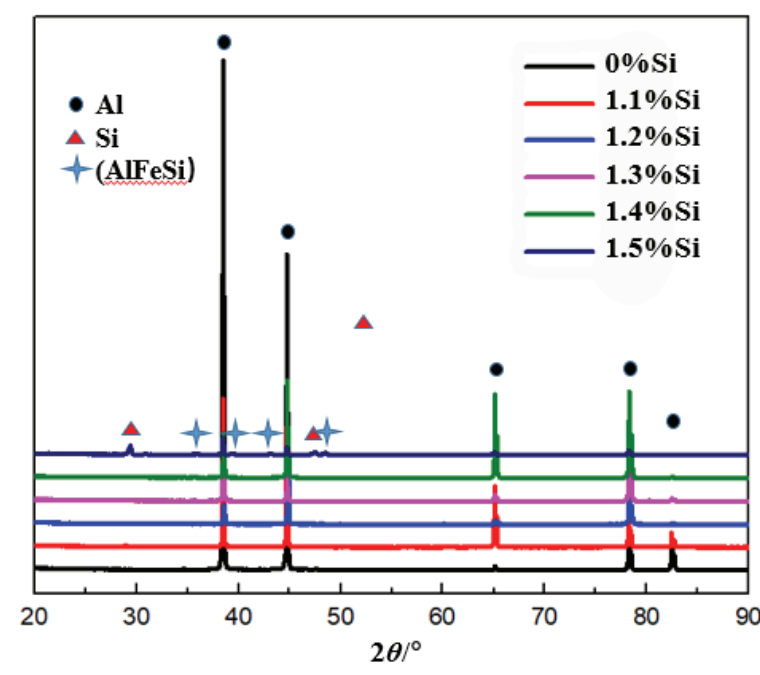

Figure 1. The XRD pattern of 8079 alloy with different Si content.

Figure 2 illustrates the evolution of the size and morphology of $\alpha-\mathrm{Al}$ and Si phases in 8079 aluminum alloy with different $\mathrm{Si}$ content. Figure $2 \mathrm{~A}$ indicates the size of $\alpha-\mathrm{Al}$ is about $80 \mu \mathrm{m}$, most of the grains are columnar implies that the property of alloy worse than that of equiaxed crystal. Figure $2 \mathrm{~B}$ shows the $\mathrm{Si}$ phase with needle like is less and mostly distributed in the intergranular as the second phases with $1.1 \% \mathrm{Si}$. When the Si content increased to $1.2 \%$ and $1.3 \%$, the grain size decreases obviously, while the Si phase with needle or particle increases, and distributed in the intergranular and grain boundary as shown in figure $2 \mathrm{~B}$ and $2 \mathrm{C}$. Further increasing the Si content (figure 2D), the grain size of the $\mathrm{Al}$ phase will not change any more, but the Si phase will grow up. When the Si content is $1.5 \%$ (figure 2E), the grain size of the $\alpha-\mathrm{Al}$ phase is about $50 \mu \mathrm{m}$, and the Si phase with the size of growth and the number of increases distributed in the intergranular and the grain boundary. That is to say, the more Si content, the more conducive to the growth of Si phase.

Figure 3 shows the EDS images of 8079 aluminum alloy with $1.3 \% \mathrm{Si}$ content. It can be seen that some casting defects in the sample, $\mathrm{Mg}$ and $\mathrm{Cu}$ are evenly distributed in the alloy, and they form stable intermetallic compounds. The distribution of $\mathrm{Al}, \mathrm{Si}$ and $\mathrm{Fe}$ is uneven, and the segregation of $\mathrm{Si}$ and $\mathrm{Fe}$ are the segregation to the grain boundary which contrary to Al. It may be that, with the increase of Si content, the number of $\mathrm{Si}$ rich particles or $\mathrm{Si}$ phase formed causes the increasing of Si phase. The 
Al phase cannot well stabilize the Si phase, which lead to uneven particle distribution and the formation of iron Fe second phases. Moreover, the deposited Si particles may block the connection structure of $\mathrm{Al}$ matrix, resulting in more defects in the material.

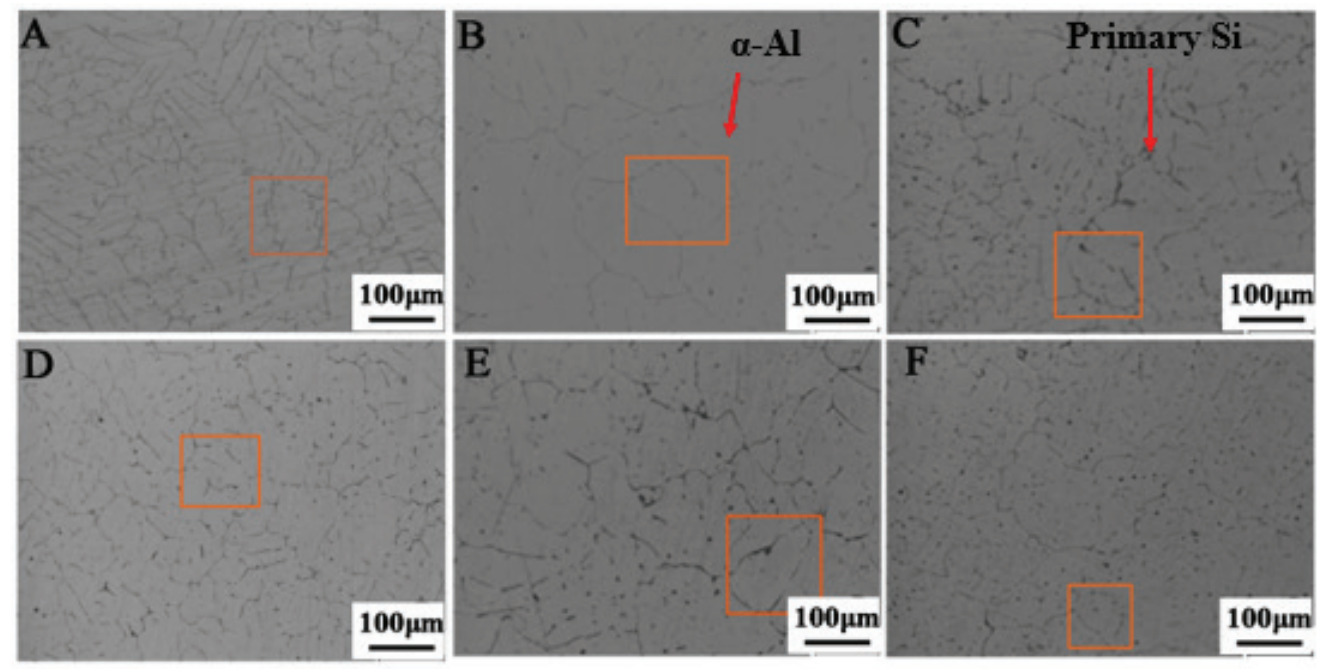

Figure 2. OM images of the 8079 alloy with different Si content, A: 0\%Si B: 1.1\%Si, C: $1.2 \% \mathrm{Si}, \mathrm{D}: 1.3 \% \mathrm{Si}, \mathrm{E}$ : $1.4 \% \mathrm{Si}, \mathrm{F}: 1.5 \% \mathrm{Si}$.
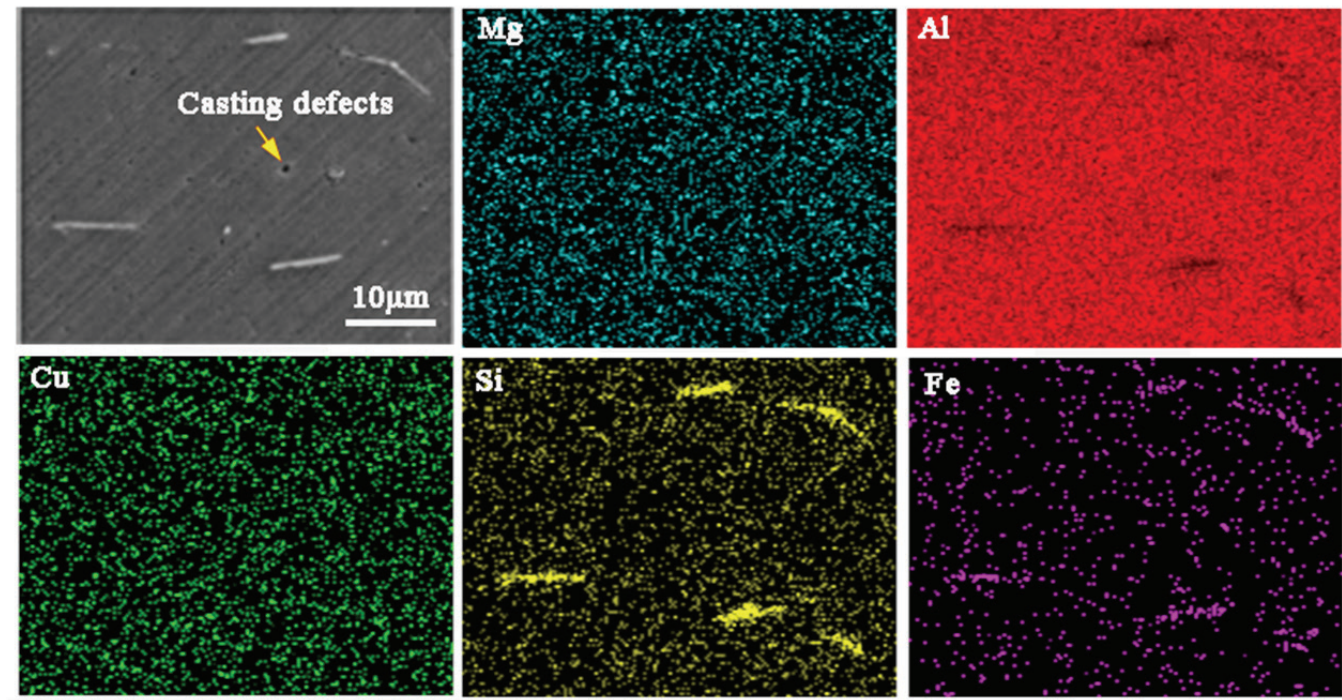

Figure 3. EDS analysis of 8079 alloy with $1.3 \%$ Si content.

\subsection{Mechanical properties}

Figure 4 indicates the tensile strength and elongation of 8079 aluminum alloy with different Si content. The alloy has high plasticity and low strength without $\mathrm{Si}$. The tensile strength and elongation of the alloy with $1.1 \%$ Si content are about $130 \mathrm{MPa}$ and $28 \%$, respectively. The tensile strength of the alloy with $1.2 \%$ Si content rise to $143 \mathrm{MPa}$, and the elongation is similar (about 28\%). When Si content is $1.3 \%$, the tensile strength and elongation are $152 \mathrm{MPa}$ and $35 \%$, respectively. Compared to the $1.1 \%$ Si alloy, the tensile strength and elongation of 8079 aluminum alloy are enhanced by $16.9 \%$ and $25 \%$, respectively. However, the tensile strength of the alloy with $1.4 \%$ and $1.5 \% \mathrm{Si}$ content are reduced to $135 \mathrm{MPa}$ and $130 \mathrm{MPa}$, and the elongation reduced to about 33\%. So the tensile strength and elongation of 8079 aluminum alloy are first increase and then decrease with the increase of Si content. When the $\mathrm{Si}$ content is small, the primary $\mathrm{Si}$ is mostly in the alloy, its microstructure is fine, and its distribution is even or dispersive. The Si phase can be used as the second phases of dispersion distribution, which greatly improving the strength of the alloy. When the Si content is higher than $1.3 \%$, the fine grain strengthening and the second phases strengthening mechanism which play the main role in alloy will decrease because of the increase of Si phase, coarsening and Fe-rich phase. The coarse Si phase and the Fe-rich phase (AlFeSi) are brittle phase, which are easy to become the crack source in the process of material deformation. 
In addition, with the increase of $\mathrm{Si}$ content, there are more voids which exists stress concentration in the alloys are suitable for the formation and growth of microcracks, which leading to the fracture of materials and reducing the strength and toughness of the alloy.

The hardness of 8079 aluminum alloy with different Si content are indicated in Table 1 . It is shown that the hardness of alloy with $1.1 \% \mathrm{Si}$ is $36.8 \mathrm{HV}_{0.2}$ is like without Si. When the Si content is $1.2 \%$ and $1.3 \%$, the hardness of alloys is raised to $41 \mathrm{HV}_{0.2^{\circ}}$. But there is a downward trend when the Si content increase, the growth trend of Si phase is larger, and the partial segregation of Si particles in the material is easy to occur. This kind of segregation often blocks the continuous contact of Al phase, and the Al liquid fills the pores between Si particles. This phenomenon leads to obvious defects in the material, then the mechanical properties of the material is declined.

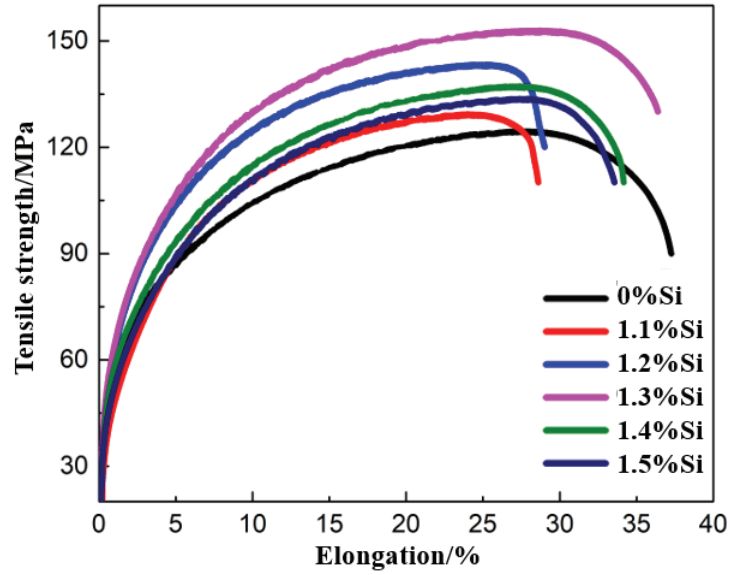

Figure 4. The tensile properties of 8079 alloy with different Si content.

Table 1. The hardness of 8079 aluminum alloy with different Si content

\begin{tabular}{lllllll}
\hline Si wt $\%$ & 0 & 1.1 & 1.2 & 1.3 & 1.4 & 1.5 \\
\hline Hardness $\left(\mathrm{HV}_{02}\right)$ & $35.7 \pm 1$ & $36.8 \pm 1$ & $41.1 \pm 1$ & $41.2 \pm 2$ & $36.9 \pm 2$ & $31.9 \pm 1$ \\
\hline
\end{tabular}

\section{Conclusion}

The thickness of $8079 \mathrm{Al}$ alloy is gradually thinning due to conserve energy and reduce emissions, and the processing technology of double zero $\mathrm{Al}$ foil is more intelligent, which requires that the raw materials of aluminum foil have better mechanical properties. Si is the main component of the material, which has a great influence on the grain size and phase distribution. By the analysis and discussion, the conclusions were drawn as follow:

(1) The addition of $\mathrm{Si}$ can refine primary a-Al phase and the mean grain size was decreased by $33.3 \%$ from $75 \mu \mathrm{m}$ to $50 \mu \mathrm{m}$.

(2) When the Si content was less than $1.3 \%$, the $\mathrm{Si}$ phase as the second phases was less which needle like, mostly distributed in the intergranular. When the Si content was more than $1.3 \%$, the Si phase grown up, the amount of $\mathrm{Si}$ increased at the intergranular and grain boundary. The more $\mathrm{Si}$ content, the more favorable for the growth of $\mathrm{Si}$ phase.

(3) When Si content was $1.3 \%$, the tensile strength, the elongation and the hardness with the highest value were $152 \mathrm{MPa}, 35 \%$ and $41.2 \mathrm{HV}_{0.2}$, respectively.

Acknowledgments: This work was financed by Aluminum Corporation of China Limited Qinghai Branch (Grant No. K151879), and the Natural Science Foundation of Qinghai Province under Grant No. 2018-ZJ-957Q and No. 2020-ZJ933Q.

Author Contributions: Linhui ZHANG took out the original ideas, carried out all the experiments and prepared the draft of the manuscript. Binnian ZHONG modified the manuscript and gave suggestions in the discussion. Xiaoshu KANG carried out the experiments.
Conflict of Interest: The authors declare that there is no conflict of interest regarding the publication of this paper.

\section{References}

[1] Roy. R. K, Kar. S, Das. K, et al. A study of precipitation and recrystallization behavior of aluminum alloy AA1235[J]. Journal of Materials Science, 2006, 41 (4): 1039-1045.

[2] Lentz, M., G. Laptyeva, and O. Engler, Characterization of second-phase particles in two aluminium foil alloys. Journal of Alloys and Compounds, 2016. 660: 276-288.

[3] Schmidt C W, Mortensen D, and Harryhausen K, Influence of Process Conditions on Segregation Behavior in Twin-Roll Casting of an Al-Fe-Si-Alloy[J]. Light Metals, 2017: 811-819.

[4] Zhang J, Pan F, Zuo R, et al. The low temperature precipitation in commercial-purity aluminum sheets for foils[J]. Journal of Materials Processing Technology, 2008, 206(1-3): 382-387.

[5] Lentz M, Laptyeva G, and Engler O, Characterization of second-phase particles in two aluminum foil alloys, Journal of Alloys and Compounds, 2016, 660(5): 276288.

[6] Birol $Y$, Formation of pinch marks on pack rolled aluminum foil[J], Engineering Failure Analysis,2013, 28(3): 82-89.

[7] Wei C, Pizhi Z, Qi Z, et al. Effect of degreasing annealing temperature on mechanical properties of continuous casting and rolling AA8079 aluminum alloy foil[J]. heat treatment of metals, 2015, 40(7):155-159.

[8] Qinglin Li, Yuqian Zhu, Shang Zhao, et al. Influences of $\mathrm{Fe}, \mathrm{Mn}$ and $\mathrm{Y}$ additions on microstructure and 
mechanical properties of hypoeutectic Al-7\%Si alloy[J]. Intermetallics, 2020, 120: 106768.

[9] Schmidt C. W, Mortensen. D, and Karhausen. K, Influence of Process Conditions on Segregation Behavior in TwinRoll Casting of an Al-Fe-Si-Alloy[J]. Light Metals, 2017, 811-819.

[10] Zhang J, Pan F, Zuo R, et al. The low temperature precipitation in commercial-purity aluminum sheets for foils[J]. Journal of Materials Processing Technology, 2008, 206(1-3): 382-387.

[11] Roy. R. K, Kar. S, Das. K, et al. A study of precipitation and recrystallization behavior of aluminum alloy AA1235[J]. Journal of Materials Science, 2006, 41 (4): 1039-1045.

[12] D. Liang, W. Jie, H. Jones. The effect of growth velocity on primary spacing of Al3Fe dendrites in hypereutectic Al-Fe alloys[J]. Journal of Crystal Growth, 1994, 135(34): 561-564.

[13] C.-Y. Ban, Y. Han, Q.-X. Ba, et al. Effect of magnetic field on the morphology and distribution of Al3Fe phase in hypereutectic Al-Fe alloy[J]. Journal of Northeastern University, 2010, 31(9): 1278-1282.

[14] Belmares-Perales S, M. Castro-Román, Herrera-Trejo $\mathrm{M}$, et al. Effect of cooling rate and $\mathrm{Fe} / \mathrm{Mn}$ weight ratio on volume fractions of $\alpha$-AlFeSi and $\beta$-AlFeSi phases in $\mathrm{Al}_{7.3} \mathrm{Si}_{3.5} \mathrm{Cu}$ alloy[J]. Metals \& Materials International, 2008, 14(3): 307-314.

[15] V. Stefániay, á. Griger, Turmezey T. Intermetallic phases in the aluminium-side corner of the AlFeSi-alloy system[J]. Journal of Materials Science, 1987, 22(2): 539-546.

[16] Kuijpers NCW, Vermolen FJ, VuikC, et al. The dependence of the $\beta$-AlFeSi to $\alpha$-Al(FeMn)Si transformation kinetics in Al-Mg-Si alloys on the alloying elements[J]. Materials Science \& Engineering A Structural Materials, 2005, A394(1/2): 9-19.

[17] V. Stefániay, Á. Griger, T. Turmezey. Intermetallic phases in the aluminium-side corner of the AlFeSi-alloy system[J]. Journal of Materials Science volume,1987, 22: 539-546.

[18] R.J.Davues, V.Randle, G.J.Marshall. Continuous recrystallization-related phenomena in a commercial AlFe-Si alloy[J]. Acta Materialia, 1998, 46(17): 6021-6032.

[19] Ahmet Can, Hüseyin Arikan, Kadir Çýnar. ANALYSIS OF TWIN-ROLL CASTING AA8079 ALLOY $6.35-\mu \mathrm{m}$ FOIL ROLLING PROCESS[J]. Materials and technology,2016, 50 (6): 861-868.

[20] Christoph Heering, Xiaoli Li, Markus Bambach, et al. Physical and Numerical Simulation of Cold Rolling of an AIFeSi Alloy in Consideration of Static Recovery[J]. Advanced Engineering Materials, 2010, 12(3): 141-146.

[21 Wei C, Pizhi Z, Qi Z, et al. Effect of degreasing annealing temperature on mechanical properties of continuous casting and rolling AA8079 aluminum alloy foil[J]. Heat Treatment of Metals, 2015, 40(7): 155-159. 